\title{
Science Academies' Refresher Course in Molecules and Materials Characterization
}

\author{
Organized by \\ Department of Chemistry \\ Salipur Autonomous College, Salipur \\ Cuttach, Odisha \\ February 01-14 2018 \\ Sponsored by \\ Indian Academy of Sciences, Bengaluru \\ Indian National Science Academy, New Delhi \\ The National Academy of Sciences, India, Allahabad
}

The Course is aimed for college teachers of Chemistry/Applied Chemistry/Materials Chemistry, etc. at $\mathrm{BSc} / \mathrm{MSc}$ and at research level. It will cover different analytical techniques involved for characterization, through lectures and out of which two days will be experimental work at Department of Chemistry, Ravenshaw University with instruments like NMR, FTIR, GC, GC-MS, UV-Visible, fluorescence spectroscopy, cyclic voltametry, etc., with illustrative problems. Some advanced topics, and common difficulties faced by students will also be discussed. College/University teachers and research workers with at least a master's degree in Chemistry/Applied Chemistry/Materials Chemistry etc. are encouraged to apply. Preference will be given to College/University teachers.

Topics: There will be courses dealing with, molecular, resonance, lumination spectroscopy and its instrumentation. XPS, UPS, Mossbauer, UV-Visible, NMR Spectroscopy, mass spectrometry, electroanalytical techniques, optical activity, surface enhanced Raman scattering, catalytic activity, electronic and nanoelectronic properties, thermal analysis, X-ray diffraction, determination of surface acidity and basicity, liquid and gas chromatography, group theory to electronic spectra, applications of symmetry to Raman and IR active bands, non thermal plasma, fast dynamics, ion-solvent interaction, AFM, SEM, magnetic microscopy, Ac susceptibility, Dc magnetometry and susceptometry.

Resource Persons: Prof. Ashok Kumar Mishra [IIT Madras], Prof. T Pal [IIT Kharagpur], Prof. Ashutosh Ghosh [University of Calcutta], Prof. Dillip K Maiti [University of Calcutta], Prof. N N Das [Utkal University], Prof G C Pradhan [Utkal University], Dr S P Das [Ravenshaw University] and Dr Subhankar Bedanta [NISER, Bhubaneswar]. Teachers/research scholars who wish to participate should send a short letter explaining their reasons for wanting to participate, along with brief curriculum vitae (including name, date of birth, gender, educational qualifications, teaching experience, typical courses taught, positions held, postal and email address, and contact numbers).

Applications are to be submitted ONLINE by clicking the following link:

http://web-japps.ias.ac.in: 8080/Refreshcourse/JBJB.jsp

Course Director: Prof. Ashok Kumar Mishra. A printed copy of the application approved by the Head of the Institution to be sent to the Course Coordinator: Dr. Asit Parija. (asitparija2k8@ yahoo.com) Department of Chemistry, Salipur Autonomous College, Salipur. Cuttack. Odisha.Pin:754202.

Selected participants will be provided local hospitality. Outstation participants will be reimbursed round trip 3-tier train fare (shortest route) from place of residence. Participants are expected to stay for the full duration of the course.

Last date for receipt of application: November 30, 2017. 